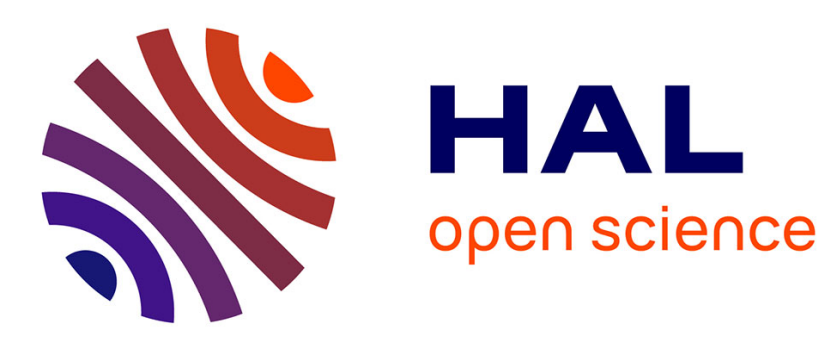

\title{
Decision-making based on network visualization applied to building life cycle optimization
}

\author{
Gilles Fraisse, Bernard Souyri, Ioannis Axaopoulos, Simon Rouchier
}

\section{To cite this version:}

Gilles Fraisse, Bernard Souyri, Ioannis Axaopoulos, Simon Rouchier. Decision-making based on network visualization applied to building life cycle optimization. Sustainable Cities and Society, 2017, 35, pp.565 - 573. 10.1016/j.scs.2017.09.006 . hal-01814480

\section{HAL Id: hal-01814480 \\ https://hal.univ-smb.fr/hal-01814480}

Submitted on 15 Nov 2018

HAL is a multi-disciplinary open access archive for the deposit and dissemination of scientific research documents, whether they are published or not. The documents may come from teaching and research institutions in France or abroad, or from public or private research centers.
L'archive ouverte pluridisciplinaire HAL, est destinée au dépôt et à la diffusion de documents scientifiques de niveau recherche, publiés ou non, émanant des établissements d'enseignement et de recherche français ou étrangers, des laboratoires publics ou privés. 


\title{
Decision-making based on network visualization applied to building life cycle optimization
}

\author{
Fraisse Gilles*, Souyri Bernard, Axaopoulos Ioannis, Rouchier Simon \\ LOCIE, UMR CNRS 5271, Université Savoie Mont-Blanc, 73376 Bourget du Lac
}

(*) corresponding author

Contact : fraisse@univ-smb.fr

Key words: Decision-making, surrogate model, computational time, multi-objective optimization, satisfaction function

\section{Highlights:}

- $\quad$ The network visualization is a very relevant tool for decision making analysis.

- In the context of life cycle optimization of whole buildings, computational time is a key issue (climate change, uncertainties, detailed model...).

- Surrogate models are very useful to reduce computation time: four strategies have been presented concerning the choice of new individuals in the adaptive design of experiments

- Satisfaction functions can be used in the adaptive design of experiment in order to reduce computational time (strategy $n^{\circ} 4$ )

\section{Abstract:}

We present a building design optimization methodology that has been developed to address issues that researchers and engineers are currently facing when addressing the life cycle optimization of Nearly Zero Energy Buildings (NZEBs). In order to reduce the required computational time, a Kriging model is used to surrogate NZEB performance criteria during the optimization process. The error estimation of the Kriging model is used for an adaptive sequential design to improve the Kriging model accuracy. A genetic algorithm (NSGA-II) is considered efficient to find the global optimal solutions. We also propose a new algorithm to reduce the calculation time even further. The new individuals of the adaptive sequential design are filtered with satisfaction functions. It means that only the useful part of the Pareto front will be determined. Finally, we use network visualization for decision-making. We show that this approach is very powerful to help designers find one solution in the context of multi-objective optimization. Moreover, the partitions can give useful information about the characteristics of the optimal solutions.

\section{Introduction}

The residential sector consumes about $40 \%$ of the total annual final energy of developed countries (IEA, 2008). In 2015, the final energy consumption of the residential sector was $25.3 \%$ of the total final energy consumption in the European Union (EU). The energy ratio used by the EU households in 2015 for space heating was $64.7 \%$, for domestic hot water 
(DHW) $13.9 \%$, for lighting and other appliances $13.8 \%$, and for air conditioning $0.5 \%$ of the total final energy of the residential sector (European commission, 2017). In an attempt to reduce the energy use in buildings, the EU applied a policy named "Energy Performance of Buildings Directive" (EPBD). The concept of "nearly Zero-Energy Buildings" (NZEB) has been defined in the EPBD : these buildings balance their small yearly energy consumption with electrical production using renewable energy. By the end of 2020, all new buildings will be required to be NZEBs.

The Energy Building Design (EBD) for NZEB is challenging in many ways. One challenge is to cover a large amount of their energy needs using renewable energy sources (RES) (N. Kalkam et al., 2012; G. Comodi et al., 2014; A. J. Marszal et al., 2011). This is problematic because RES depend highly on the climate of the building location. This means that the energy supply from RES does not always match the energy needs (S. Cao et al., 2013). The designer cannot therefore easily size, for example, the required installed power of the RES and the storage capacities (thermal and electrical) to meet the energy needs. Considering electricity, as feed in tariff variation is a downward trend, storage with batteries and self-consumption also become key issues.

Another challenge is to reduce the relatively high value of NZEBs embodied energy compared to their annual energy consumption (R. Giordano et al., 2017; R. Giordano et al., 2015; G. A. Blengini et al., 2010; M. Karimpour et al., 2014; T. Ramesh et al., 2010). Once the operational energy needs of a building during its lifetime are balanced by the use of RES, then the embodied energy, i.e. the energy used during its construction, becomes significant (Y. Chen \& S. T. Ng, 2016; P. Chastas et al., 2016; E. Ayaz \& F. Yang, 2009; R. Fieldson et al., 2009; Ibn-Mohammed T. et al., 2013). This leads the designer of a NZEB to perform life cycle analysis (LCA) which is a more comprehensive approach that includes embodied energy assessment. Considering the building life time, the designer should also account for the climate change. C. Roux et al. (2016) performed a LCA and life cycle cost (LCC) assessment and X. Song et al. (2017) an energy consumption analysis on residential buildings, both incorporating a weather data prediction on the climate on future years. To account for climate change, more dynamic simulations on possible climate scenarios are required. These extra simulations add to the overall increase of computational time.

In addition, another issue is the complexity of modeling a NZEB as a whole (envelope, systems, etc.) that increases the computational time even further. Therefore, NZEB optimization needs to reduce the required computational time using specific methodologies (M. Wetter \& E. Polak, 2004; L. Magnier et al., 2010). Moreover, the designer of a NZEB should consider many performance criteria, such as the cost, thermal comfort, embodied energy, $\mathrm{CO}_{2}$ emissions, energy consumption, RES production, durability... All of the factors mentioned above lead to the need for a global approach of NZEB optimization (R. Evins, 2013). Thus, the designer should perform a multi-objective optimization that will result in many possible optimal solutions. These optimal solutions can be presented in a Pareto front.

Pareto fronts can be a good tool for the decision maker to choose a solution but it can be rather impractical for more than two performance criteria. There are many different MultiCriteria Decision Making Analysis (MCDA) methods that can be used to post-process optimal 
solutions in EBD. Among these MCDA methods are TOPSIS e.g. used by Q. Jin et al. (2017), E. Wang et al. (2017); Analytical Hierarchy Process (AHP) e.g. used by J. Si (2016), F. Roberti (2017), E. Mulliner (2016); Elimination and Choice Expressing the Reality (ELECTRE) e.g. used by T. Catalina (2011); Complex Proportion Assessment (COPRAS) e.g. used by R. Volvačiovas(2013), E. Mulliner(2016); SMAA (Stochastic Multi-criteria Acceptability Analysis) e.g. used by J. Iwaro (2014) and Stochastic Multicriteria Acceptability Analysis used by K. Kontu (2015). Furthermore, it is not common in EBD literature, to use decision making tools before post-processing, i.e. integrated in the optimization algorithm (M. S. Cherif, 2008). This could help reduce calculation time if the optimal solutions of little interest were not considered.

Building and energy systems optimization is currently a very active research area. Many authors are interested in optimizing a building's envelope and energy systems considering more than one performance criteria, i.e. multiobjective optimization (MOO) (E. Antipova et al., 2014; J. Carreras et al., 2014), like Wu et al. (2017) that apply a mixed integer linear program (MILP) optimization to minimize both the greenhouses gas (GHG) emissions and the life cycle cost of buildings' energy systems and envelope on a community level. Others, like Penna et al. (2015) take three objectives into account (energy savings, costs and indoor thermal comfort) and apply the NSGA-II algorithm to define the optimal energy measures on a building as a whole, including both energy systems and envelope. Moreover, Evins, R. (2013), Attia, S. (2013) and Machairas, V. (2014) have presented detailed literature reviews on optimization methods, used for EBD. In reviewed EBD literature it is less common to optimize more than three objective functions simultaneously (Penna P., 2015).

The commonly used algorithms in building energy efficient design optimization can be grouped into three categories, namely evolutionary algorithms, gradient-based search algorithms, and hybrid algorithms (K. Terzidis, 2006). Several reviews that focus on performance-based building design optimization or similar methods are available. Evins, R. (2013) conducted a review on computational optimization methods applied to sustainable building design. Nguyen et al. (2014) reviewed simulation-based optimization methods in building performance analysis. Machairas et al. (2014) took a different angle and reviewed the algorithms used in performance-based building design optimization. Attia et al. (2013) reviewed the gaps and needs for integrating building performance optimization tools in NZEB design.

A current trend in EBD optimization is to reduce computational time using surrogate models (SM) to mimic time-costly transient simulation models. Carreras et al. (2016) apply an optimization of two objectives, to minimize cost and environmental impact of a building envelope using a SM (cubic spline interpolation) to reduce computational time.

These SM may be classified based on their employed techniques: Radial basis function, Kriging (KR), support vector regression (SVR), artificial neural network (ANN), multivariate adaptive regression splines (MARS), and others. Bornatico et al. (2013) respectively apply Radial basis function surrogate modeling on a MOO to maximize solar yield and to minimize investments costs of a solar domestic hot water (SDHW) system. Kriging is a non-parametric technique, suitable for the identification of long term temporal and spatial trends (Zavala 
VM et. al, 2009). Furthermore, one of its special features is the ability to predict not only numerical values, but also uncertainty boundaries. Many authors use Kriging to predict building energy performance, as C.J. Hopfe et al. (2012), E. Tresidder et al. (2016), Van Gelder, L. et al. (2014) and P. Eguía et al. (2016).

A different technique with similar applications is Support Vector Machines (SVM). The main advantage of SVM over ANN is related to the fact that the statistical learning process is cast as a convex optimization problem (Boyd SP et al., 2004). B. Eisenhower et al. (2012) uses SVM to perform a model-based MOO to minimize thermal discomfort (PMV) and annual energy consumption.

ANN is a parametric technique that has the ability to learn complex patterns (Beccali et al., 2004) and simulate non-linear systems (Karanachos A et al., 1998). Also, ANN is efficient in building studies (Magnier, L., \& Haghighat, F., 2010). It is the dominant technique for building energy performance (Ascione et al., 2017).

However, in the case of a time-consuming transient simulation model, KR has a far lower training time compared to ANN because less samples would be needed. Usually, in EDB literature, Multivariate Adaptive Regression Splines (MARS) are preferred to KR because of their simplicity and clear relationship between inputs and outputs (Van Gelder, L. et al. , 2014).

MARS is an adaptive non-parametric regression method (Friedman J. H., 1991). MARS has seen surprisingly little application in building-related studies to date (Cheng, M. Y., \& Cao, M. T., 2014). Kusiak, A. et al. (2010) compares MARS to other SM in a model-based MOO problem, using a Particle swarm optimization (PSO) algorithm to minimize the energy consumption of a HVAC system.

Sequential design strategies for SM have been studied in the context of deterministic computer experiments, to perform either prediction or optimization (Kleijnen, 2017). Cheng, M. Y., \& Cao, M. T. (2014) used a hybrid technique, MARS and artificial bee colony in adaptive design of a SM to predict heating and cooling load of buildings. Ramallo-González et al. (2014) apply a Covariate Matrix Adaption Evolutionary Strategy (CMA-ES-SA) optimization, to minimize cooling and heating demands of a building.

In the following sections, we present an EBD optimization methodology that has been developed to address issues that researchers and engineers are currently facing with the life cycle optimization of NZEBs. In order to reduce the required computational time, a Kriging model is trained to surrogate NZEB performance criteria during the optimization process. The error estimation of the Kriging model is used for an adaptive sequential design to improve the Kriging model accuracy. A genetic algorithm (NSGA-II) is implemented to find the global optimal solutions. We also propose a new algorithm to reduce the calculation time even more. The new individuals of the adaptive sequential design are filtered with satisfaction functions (Cherif, 2008). It means that only the useful part of the Pareto front will be determined. Finally, we use network visualization for MCDA. We show that this approach is very powerful to help designers find one solution in the case of multi-objective 
optimization. Moreover, the partitions can give useful information about the characteristics of the optimal solutions.

\section{Methodology}

The main idea behind the methodology is to perform multi-objective optimization in the smallest possible number of transient simulations, in order to decrease computational cost. As the SM needs to be calibrated, the methodology is based on an adaptive sequential design combining (figure 1):

- Time consuming transient simulations (TRNSYS software) that feed a data base. The objective functions $f(x, y)$ are calculated with the simulations results. The decision parameters are $x$ and the other variables $y$.

- The data base $\{x, f(x)\}$ is used to calibrate the surrogate models.

- Each surrogate model (Kriging model) calculates one objective function $f^{*}(x)$ with the decision parameters $x$ as inputs.

- Multi-objective optimization (NSGA-II) is performed with the surrogate model $f^{*}(x)$

The main challenge is to determine new points $x_{\text {new }}$ in order to properly calibrate the surrogate model used to find optimal solutions. The aim is to reduce the error of the SM, particularly in the Pareto area. The new individuals can be chosen according to 4 strategies:

- Strategy $n^{\circ} 1$ : the maximal error in the whole research space (in the range of each decision parameter). The prediction error is an output of the kriging model.

- Strategy $n^{\circ} 2$ : the maximal error in the Pareto area only

- Strategy $n^{\circ} 3$ : hybrid strategy (first strategy $n^{\circ} 1$, then strategy $n^{\circ} 2$ )

- Strategy $n^{\circ} 4$ : strategy $n^{\circ} 3$, with the maximal error in the Pareto area only, and a minimum level of satisfaction. The satisfaction functions are determined by the decision maker (Cherif, 2008).

The stopping criterion for the adaptive design requires that no improvement in the Pareto front occurs. In the end, the satisfaction functions and the network visualization are used for decision making aid. In the following, the presented case study follows strategy $n^{\circ} 1$. 


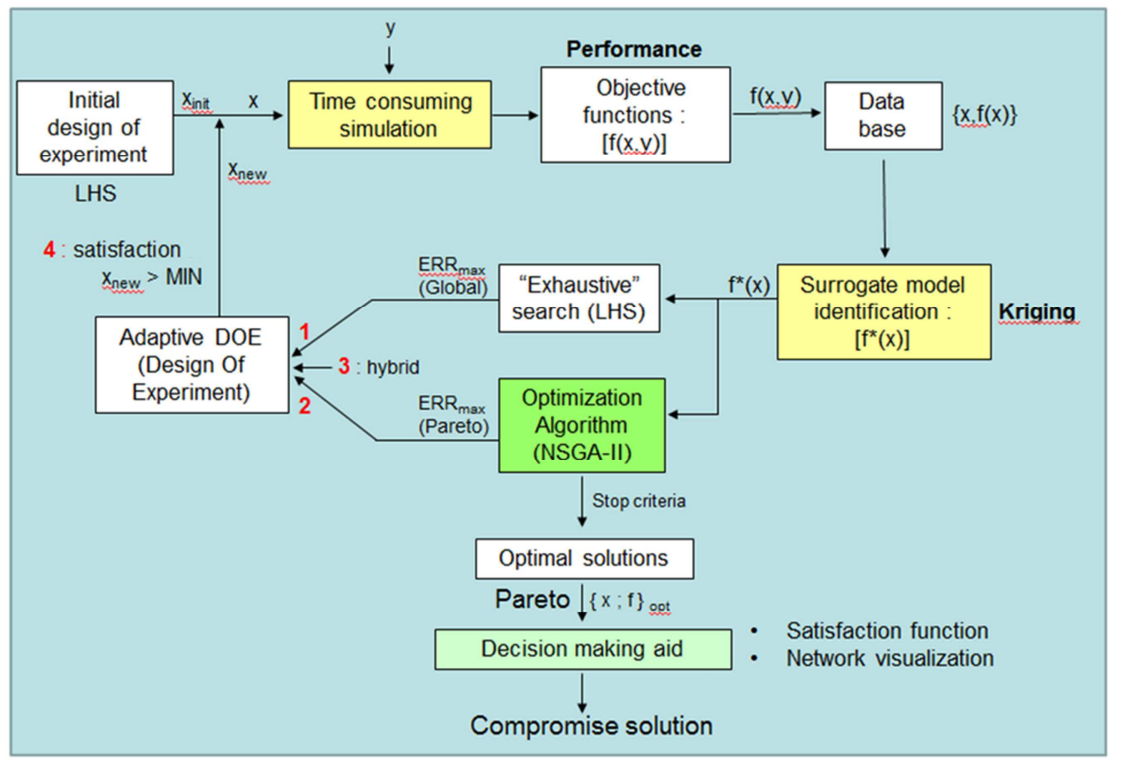

Figure 1: Presentation of the methodology (with LHS: Latin Hypercube Sampling)

\section{Case study}

The results presented concern the strategy $n^{\circ} 1$ of the general methodology (figure 1 ). The kriging models for each performance function are developed with MATLAB. The optimization is also performed with MATLAB based on genetic algorithms (NSGA-II). Transient simulations are performed with the TRNSYS 17 software. The building is modeled using the TRNSYS type 56 with respect to the envelope. The validation of the model was carried out by comparison with two other dynamic simulation tools.

\subsection{The building}

The case study concerns the design optimization of two buildings located in Chamberry (Savoie, France). The two residential buildings (34 apartments, see figure 2) have been modeled using three transient simulation software (TRNSYS, Pleaides-Comfie and Energy +). Each building is modeled under TRNSYS with only 2 zones (heated / unheated), because we first favored a fine modeling of the systems (heating and DHW) for the development of the methodology (Figure 1). The modeling of the systems has been carried out by the CEA-INES (Savoie). A multi-zone modeling under TRNSYS (one zone per dwelling and 2 zones for unheated volumes) was also carried out in parallel by LGCB (Vaulx-en-Velin, France); it will be tested later. Multi-zone modeling under Pleiades-Comfie was carried out (36 thermal zones) by the organization Armines (Ecole des Mines, Paris), but with a simplified approach for the systems. The same multi-zone modeling is developed under Energy+ by the company Albedo Energy (Savoie), but without any systems. 


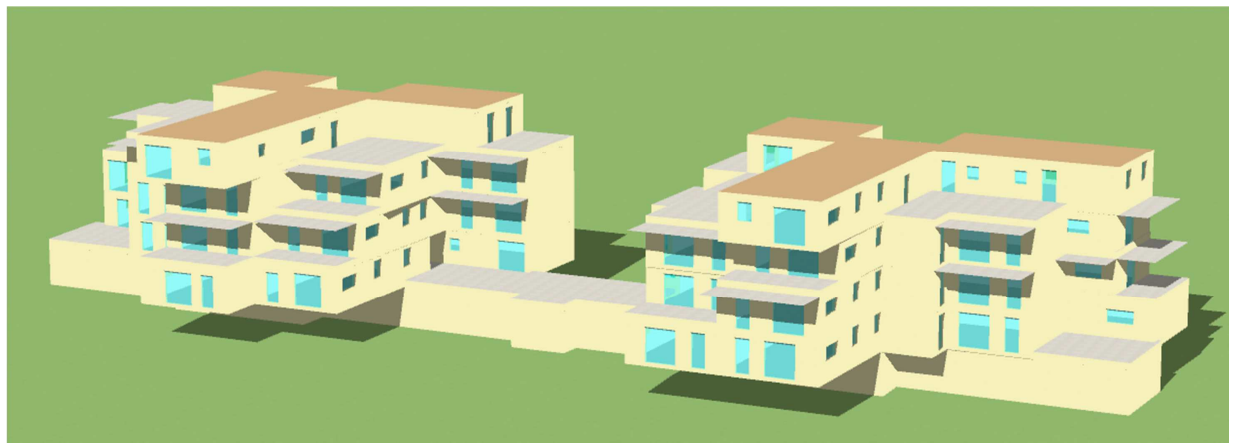

Figure 2: The 2 residential buildings (FAURE Architect, Pleaides-Comfie modeling by Armines)

The simulations show quite good agreement between the numerical tools (figure 3 ). The left-hand side figure shows the power rate change during the coldest week. The right-hand figure shows the average temperature during winter and the maximal temperature during summer. The temperature is a weighted value according to the areas of the heated zones (1 apartment $=1$ thermal zone), except for TRNSYS as we considered only 1 heated zone for each building.
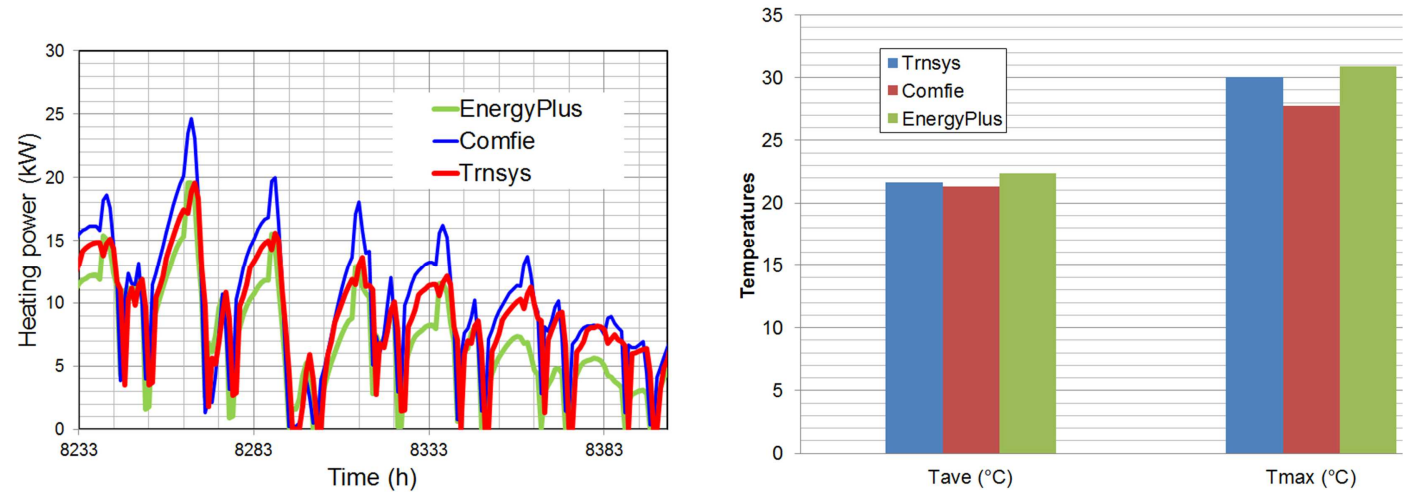

Figure 3: Comparison of simulations between TRNSYS / Energy + and Pleiades-Comfie (heating power on the left side and maximal temperature in summer on the right side)

The three simulation tools obviously allow multi-zone modeling of the building. The choice of TRNSYS was made in view of the large library of models available for the systems. Indeed, the work of modeling systems is clearly the most time consuming, compared to the envelope. The Pleiades-Comfie software is particularly interesting for the ease of modeling the envelope and the possibility of coupling with the EQUER life-cycle analysis tool. It also offers NSGA-II optimization capabilities. Surrogate models are of lesser interest in the case of Pleaides-Comfie because it works with reduced envelope models and highly simplified models for systems (thermal regulation approach). Regarding Energy + , it is a very powerful tool for the envelope and it is widely used because there's a free version. In contrast, the system model library is less developed compared with TRNSYS. This constitutes a major disadvantage for the optimization of a "high" number of system configurations.

\subsection{The climate}


We have used the climate change world weather file generator (CCWorldWeatherGen), which is available on web site : http://www.energy.soton.ac.uk/ccworldweathergen/. Based on global grid of scenario A2 for 2020, 2050 and 2080, it transforms a "present day " weather file (figure 4). Morphing' methodology for climate change transformation of weather data, was developed by SE Belcher (2005).

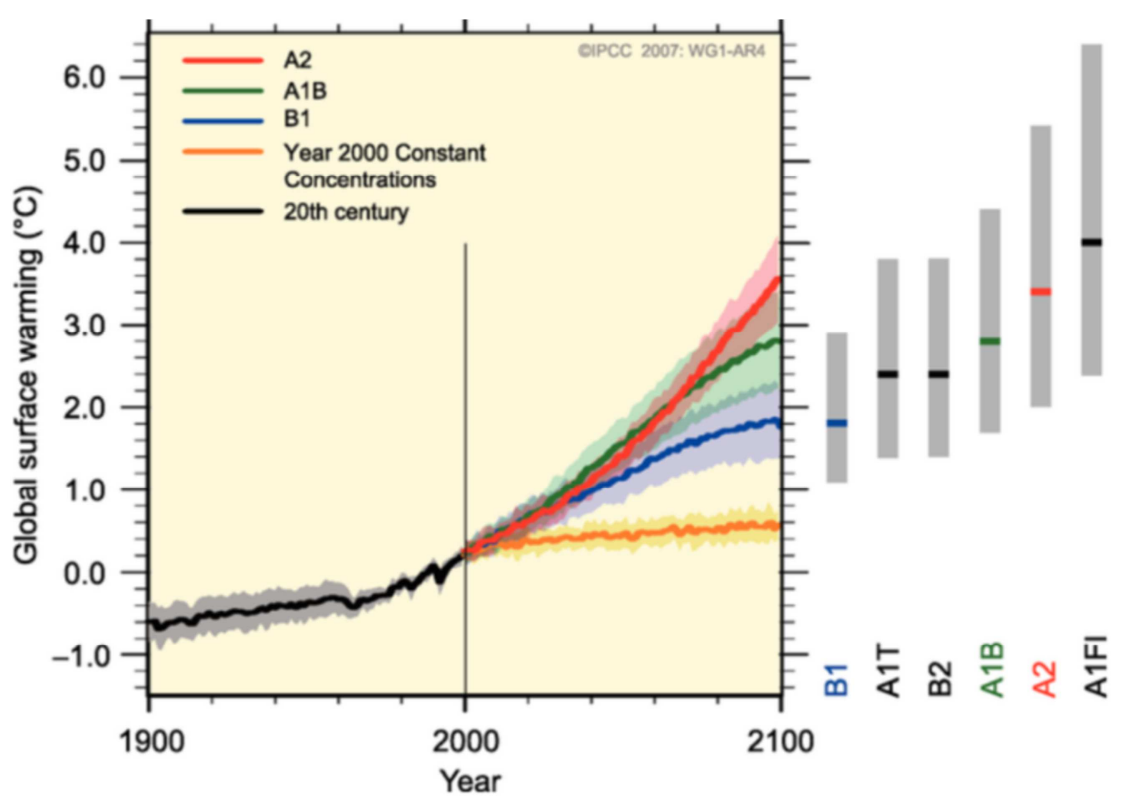

Figure 4: The climate change scenarios

We have used the A2 scenario. Tendencies on both irradiance and temperature are clearly to increase over the next years. Maximum temperature will rise of around 12 degrees. Irradiance also will rise, in a smaller rate. These climate changes will result a fall of $30 \%$ (6427 kWh/year) in heating demands from year 1995 to year 2050 (figure 5). It shows that it is necessary to consider the climate change for life cycle optimization.

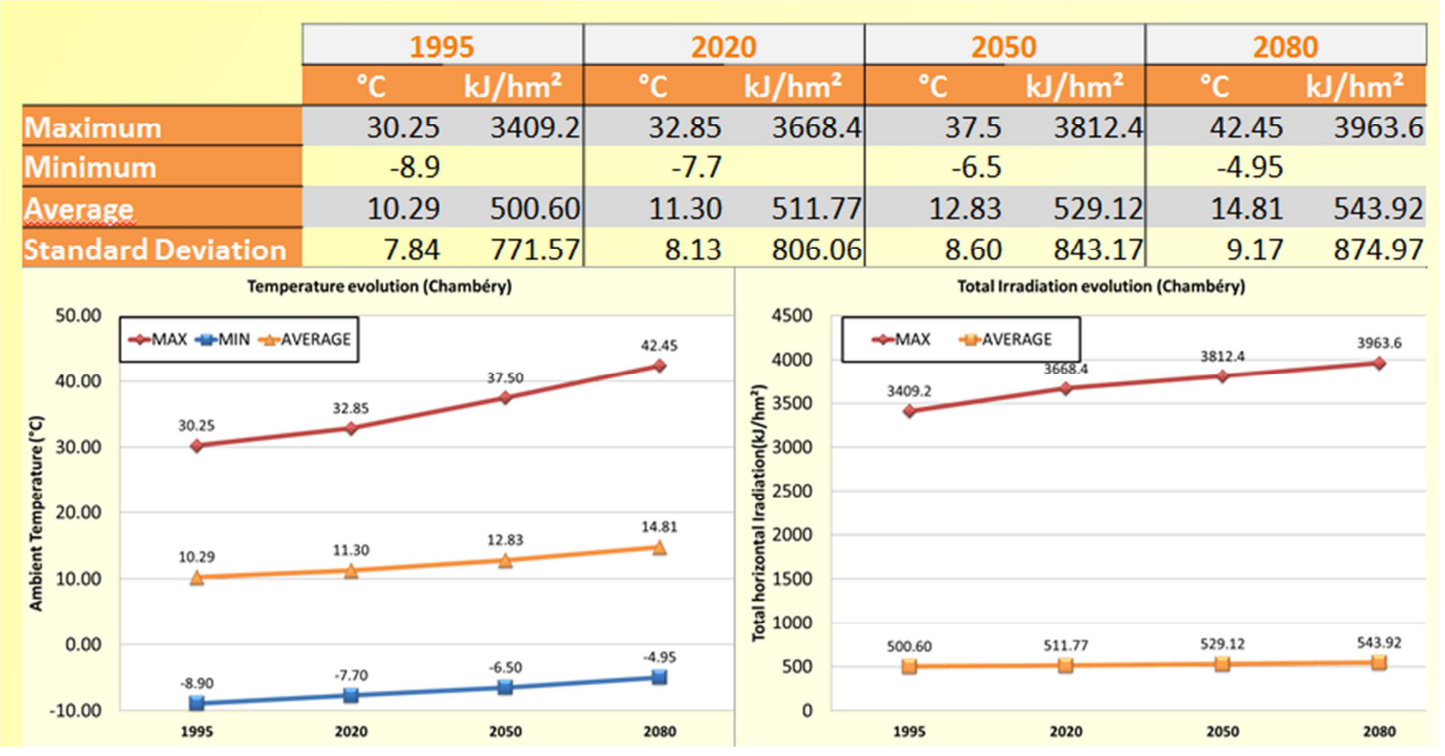


Figure 5: The heat demand ( $k W h$ ) and internal temperature (max and mean) variations

\subsection{Building configurations}

Optimization has been carried out with the initial configuration of the two buildings (concrete, external insulation, collective gas boiler, solar hot water system, exhaust mechanical ventilation system). Other configurations can be considered for optimization. They concern heating / DHW systems and the envelope. In total, we have identified 64 possible combinations of systems taking the specificities of the building and the geographical location into account:

- Combined Solar Systems (SSC) with different auxiliary heating systems

- Collective Solar Water Heaters (CESC) with different auxiliary heating systems

- Boilers using different sources of energy: gas, electricity and wood. Systems using fuel oil as primary energy were not considered due to operating costs and excessive $\mathrm{CO}_{2}$ emissions.

- Individual systems (one boiler per apartment) and collective systems (one boiler for the whole building)

- Collective or individual thermodynamic water heaters

- Heat network

- $\quad$ Air-water and water-water heat pumps

- Compact multifunction systems (ventilation with heat recovery, heat pumps, production of hot water, coupling with solar collectors...)

Regarding the envelope alternatives, these are mainly:

- type of insulation (exterior, interior, distributed)

- the nature of the insulation (glass wool, mineral-wool, polyurethane, wood-wool, polystyrene) according to the nature of the wall (façade, roof ...)

- the type of windows (double / single glazing, PVC ...), surfaces and orientations

It is not possible to combine all of the system configurations with the envelope-related configurations. It is also clear that the modeling work associated with system variants is much more time-consuming than for the envelope. Once the geometry and the thermal zones have been modeled on a configuration, changing the insulation position for example is quite simple. The main difficulty is to automatically change the thermal bridges. Also, important work has been to limit the number of systems by defining levels of relevance. In the end, we selected 9 systems:

- Collective gas boiler (with / without solar DHW)

- Individual gas boilers (with / without solar DHW)

- Water-to-water heat pump

- Collective pellet boiler (with / without solar DHW)

- Individual electric heating with solar DHW

- Heat network 


\section{Optimization hypotheses}

Since we do not develop new algorithms (NSGA-II genetic algorithms and kriging models are available under MATLAB), the main task is to implement the methodology (Figure 1), then define the objective functions and decision parameters.

\subsection{The objective functions}

We distinguished four main classes of performance: environment, cost, reliability and comfort. The life cycle of the building is considered for energy consumption and comfort taking climate change into account as we have already seen. Consumption is calculated only for several years, which makes it possible to evaluate the overall consumption after defining assumptions of energy retrofits. The life-cycle is also addressed in the life cycle cost (LCC), which is a very widespread approach to building optimization. Finally, we limited the performance criterion related to life cycle analysis to $\mathrm{CO}_{2}$ emissions (construction and energy consumption) for two reasons. The first is simply related to the importance of this criterion with respect to the greenhouse effect. The second reason concerns the interoperability difficulties between the selected LCA software (EQUER) and the TRNSYS simulation tool. Life cycle analysis can only be carried out a posteriori on some optimal solutions. We consider seven objective functions that can be evaluated using the satisfaction functions defined by the decision maker (Table 1).

\subsection{The decision parameters}

The decision parameters for the building envelope and the systems depend closely on the configurations. Each parameter has a min / max variation range. We consider only nine decision parameters (Table 2).

\begin{tabular}{|c|c|}
\hline \multirow{2}{*}{ Environment } & $\begin{array}{l}\text { Primary energy consumption (Ep): boiler and electrical appliances (pumps, } \\
\text { controller and fan) }\end{array}$ \\
\hline & $\begin{array}{l}\mathrm{CO}_{2} \text { emissions over the lifetime }\left(\mathrm{CO}_{2}\right) \text { : they depend on both the decision } \\
\text { parameters (systems and envelope) and energy consumption }\end{array}$ \\
\hline Cost & Life Cycle Cost ( $\underline{\mathbf{L C C}})$ \\
\hline \multirow[t]{2}{*}{ Durability } & $\begin{array}{l}\text { Number of hours when the temperature in the solar collector exceeds a limit } \\
\text { value ( } \underline{\text { Tmax }} \text { ) }\end{array}$ \\
\hline & Number of boiler operating cycles ( Ncycle) \\
\hline \multirow[b]{2}{*}{ Comfort } & $\begin{array}{l}\text { Thermal comfort in summer (Tint) corresponding to a number of hours when } \\
\text { the internal temperature exceeds a comfort temperature }\end{array}$ \\
\hline & $\begin{array}{l}\text { Compliance with the set temperature for hot water }(\underline{\text { Tecs }}) \text { corresponding to } \\
\text { a number of hours when the hot water temperature exceeds a temperature } \\
\text { level }\end{array}$ \\
\hline
\end{tabular}

Table 1: The objective functions 


\begin{tabular}{|c|c|}
\hline Envelope & 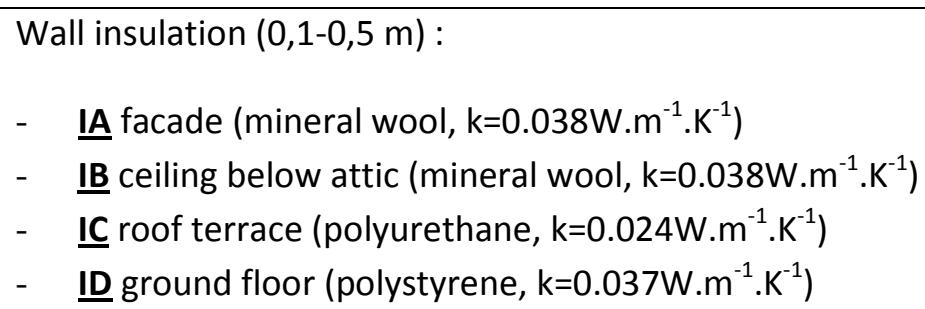 \\
\hline \multirow{4}{*}{ Systems } & Collector area $\left(\underline{\mathbf{S}}: 12-56 \mathrm{~m}^{2}\right)$ and slope (Slope : $\left.20-50^{\circ}\right)$ \\
\hline & Storage volume $\left(\underline{\mathbf{V}}: 1-4 \mathrm{~m}^{3}\right)$ \\
\hline & Boiler output rate $(\underline{\mathbf{P}}$ : $70-250 \mathrm{~kW})$ \\
\hline & Heating system temperature $\left(\underline{\mathbf{I}}: 35^{\circ}-45^{\circ}-60^{\circ} \mathrm{C}\right)$ \\
\hline
\end{tabular}

Table 2: The decision parameters

\subsection{The satisfaction functions}

In the case of a two-objective Pareto front, figure 6 illustrates MCDA method with satisfaction functions. For each objective, the decision-maker first defines the shape of the corresponding satisfaction function ( $S_{E p}$ or $S_{E}$ in figure 6). The example below shows that there is no individual in the area corresponding to $100 \%$ satisfaction for both criteria. The first individual is obtained with a satisfaction of nearly $90 \%$.

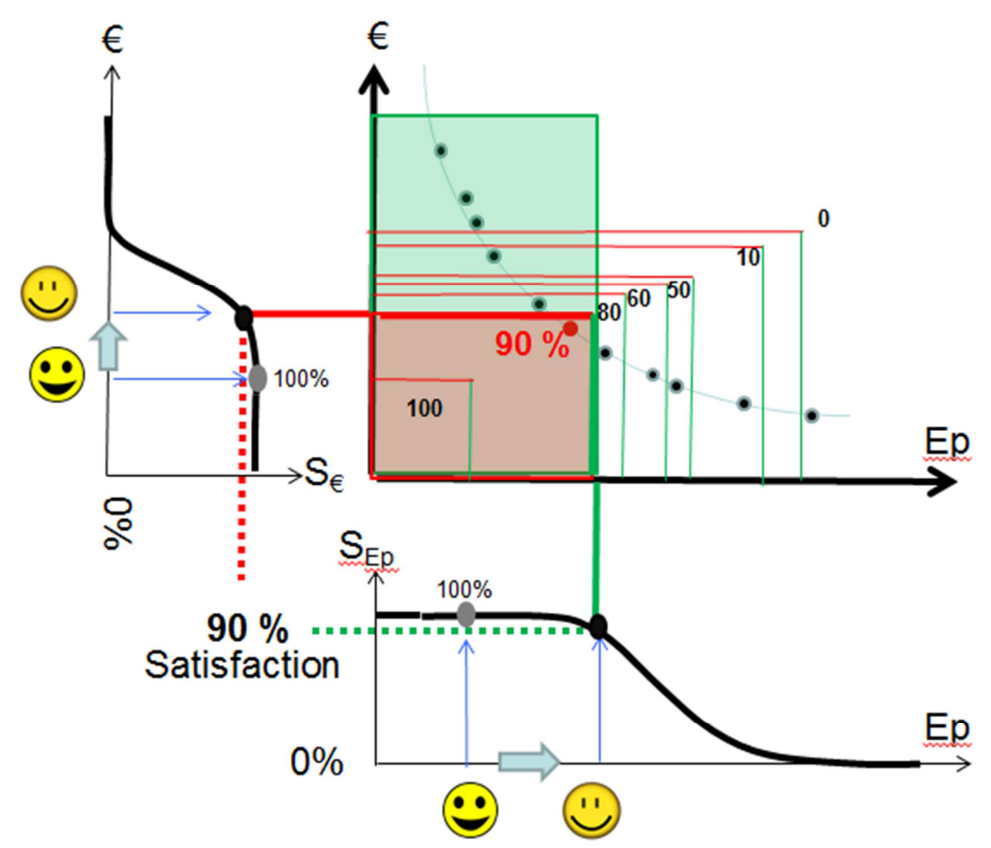

Figure 6: Illustration of decision making aid with satisfaction functions

Some individuals have zero satisfaction and are ultimately of no value to the decision-maker. Strategy $n^{\circ} 4$ presented in the general methodology (Figure 1) reduces the "useful" area of the Pareto front by requiring a minimum level of satisfaction for the new points. The 
advantage is to accelerate the convergence by limiting the scope of the optimal solutions to a useful area for the decision-maker.

On the case study of the two buildings, a sigmoid-type satisfaction function was considered for each of the seven performance functions: Ep (primary energy), $\mathrm{CO}_{2}$ (emissions), LCC (Life Cycle Cost), Ncycle (boiler durability), Tmax (solar system durability), Tint (summer comfort) and Tecs (water temperature). By way of example, figure 7 shows the satisfaction function in the case of the primary energy consumption for the optimal solutions (Pareto front). With a sigmoid type function, the curve can be determined with two points. We have decided that the decision maker gives the values of the function for the satisfactions levels 0.5 and 0.9 . Concerning energy consumption Ep, the satisfactions $S_{\mathrm{EP}}$ are respectively 0.5 and 0.9 for $60 \mathrm{kWh} / \mathrm{m}^{2}$ and $40 \mathrm{kWh} / \mathrm{m}^{2}$. In these conditions, we can easily show that:

$$
S_{E P}=\frac{1}{1+\exp \left[\frac{\operatorname{Ln}(9)}{60-40} \cdot(E p-60)\right]}
$$

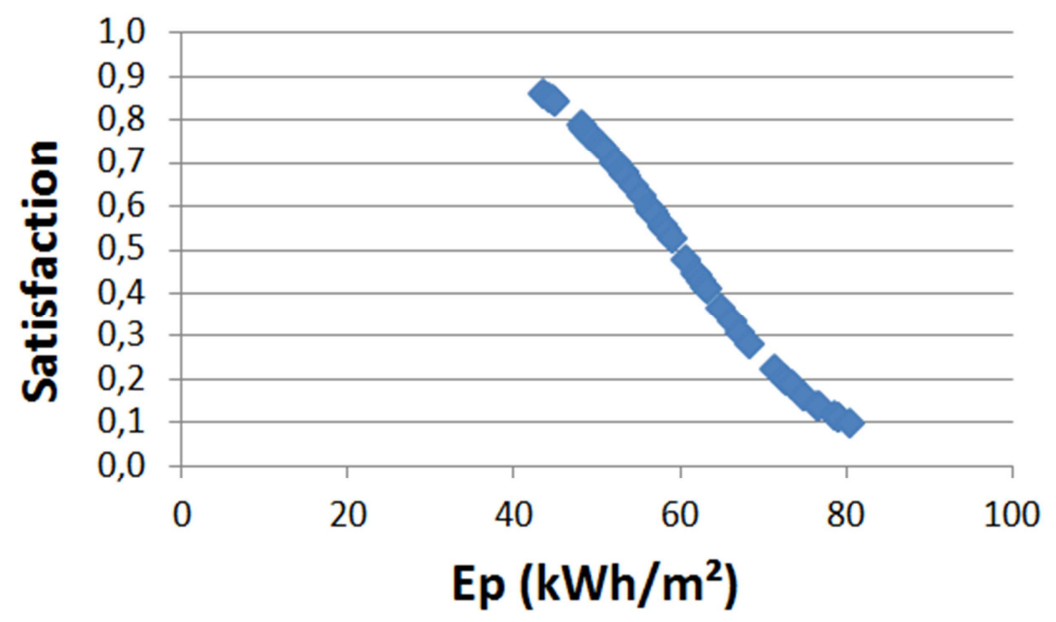

Figure 7: Example of satisfaction function defined by the decision maker in the case of optimal solutions (primary energy consumption)

We also considered a global satisfaction $\mathrm{Sg}(\mathrm{j})$ for each individual $\mathrm{j}$, by calculating a weighted (AHP, Analytical Hierarchy Process) average of the seven satisfaction functions $\overline{S_{k}}$. This overall satisfaction of an individual also considers that a solution with a high standard deviation $\sigma\left(S_{k}\right)$ between the satisfaction functions must be penalized. It means that the average satisfaction $\overline{S_{k}}$ will be reduced according to the standard deviation level. A second term is also considered in the global satisfaction. For each individual $j$, the overall satisfaction is thus calculated by the relation:

$$
S g(j)=\left(\overline{S_{k}}\right)_{j}-\alpha \cdot \sigma\left(S_{k}\right)_{j}
$$

With $\quad \alpha$ : a fixed parameter penalizing the dispersion of the satisfactions $S_{k}$ for each individual $\mathrm{j}(\alpha=-0.2$ in our study) 


\section{$k=1 \ldots 7:$ the objective functions}

The shape of the satisfaction function (figure 7) will also influence primarily the strategy $n^{\circ} 4$. The decision maker will have to carefully determine the minimum level of satisfaction which is required. Secondly, the overall satisfaction depends on each satisfaction function. The shape of each curve will thus have to be carefully determined.

Regarding the AHP method, we first considered four main classes (Environment / Cost / Durability / Comfort) shown in table 1. The decision maker has to fill in a half matrix that determines the importance of one performance compared to another one. The AHP methods can then calculate the weights for each main class. The weight for each function is calculated according to the number of these functions (table 3 ).

\begin{tabular}{|l|l|l|}
\hline Main classes & Weighting (main classes) & Weighting (functions) \\
\hline Environment & 0.30 & Ep $: 0.15 \quad$ CO $_{2}: 0.15$ \\
\hline Cost & 0.51 & LCC $: 0.51$ \\
\hline Durability & 0.10 & Tmax $: 0.05$ Ncycle $: 0.05$ \\
\hline Comfort & 0.09 & Tint $: 0.045$ Tecs $: 0.045$ \\
\hline
\end{tabular}

Table 3: The values of the weights

\subsection{Results for strategy $n^{\circ} 1$}

The Pareto front consists of 62 individuals. These optimal solutions can be classified according to the overall satisfaction defined above. Solution 2 appears as the most efficient solution.

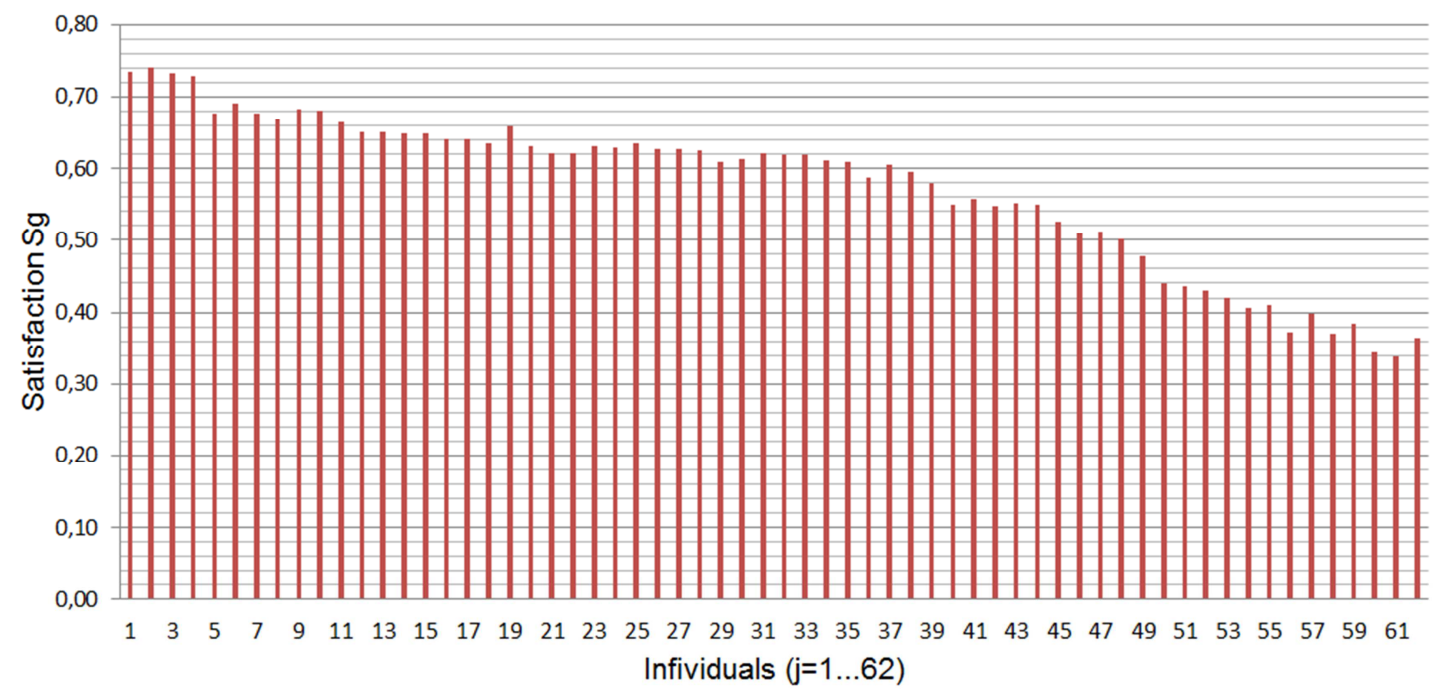

Figure 8: The satisfaction functions (0-1) for all the optimal solutions

The previous strategy of globalizing satisfaction obviously simplifies the problem by transforming a multi-criterion optimization into a single criterion. If it is desired to keep the 
seven satisfaction functions for the decision maker choice, it is very difficult to interpret conventional graphical representations of the heat map, matrix scatter plot or radar type. An original way we propose is to use the network visualization, with the Gephi software (algorithm: ForceAtlas 2). Each link between the node of a solution and the node of a criterion corresponds to the satisfaction level of the solution (an individual) for this criterion. The closer the node "individual" is to the node "criterion", the better is the satisfaction level of the individual for this criterion. We have also considered that the diameter of the node of an individual defines the overall satisfaction level. However, the diameters of the nodes representing the criteria are constant. As shown in figure 9 , individual $n^{\circ} 2$ has the largest diameter and therefore the best overall performance. It is quite close to all the nodes representing the performance functions, excluding the performance related to the comfort (Tint). The automatic partition achieved by the Gephi software reveals three large classes ( 3 different colors) in a very logical way. The criteria $\mathrm{LCC}$, Ep and $\mathrm{CO}_{2}$ belong to the same classification. These three quantities are closely related in the case of the building under consideration, which does not have photovoltaic production (it is not a NZEB building). The second and third classifications concern respectively the two functions related to durability (Tmax and Ncycle), and the two functions related to comfort (Tecs and Tint).

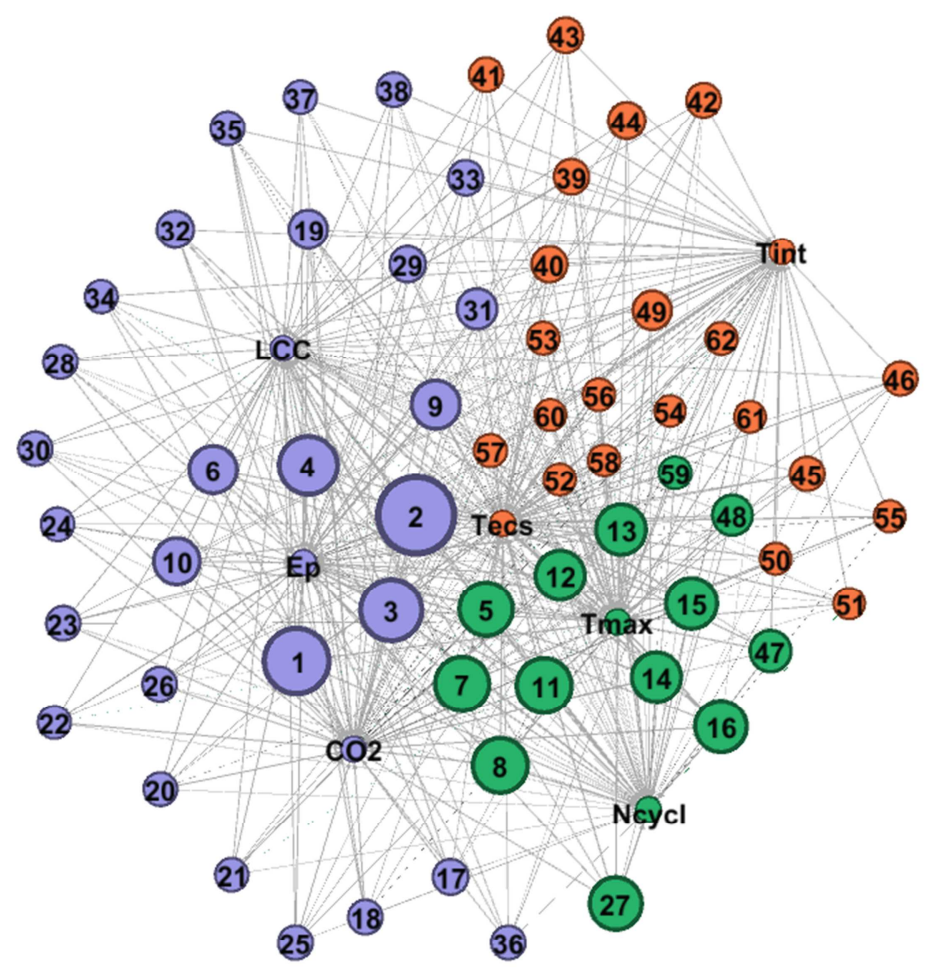

Figure 9: Links between the 62 individuals of the Pareto front and the performance criteria (a short distance between a node "individual" and a node "criterion" means that the level of satisfaction is high)

Another possible representation is to connect the nodes of the optimal solutions with the nodes of the associated values for each decision parameter. We divided the variation range 
shown in Table 2 into three for each of the nine decision parameters $(+/++/+++)$. In figure 10 , it is easy to see that the best solutions are related to:

- $\quad$ A large storage volume $(\mathrm{V}+++)$

- A large thermal solar collector area (S+++)

- A large slope of collector area (slope+++), corresponding to a range $40-50^{\circ}$

- High insulation resistance for the envelope (IA+++ , IB+++ , IC+++), excluding the ground floor (ID++) which should not be very insulated for cost issue

- A low heating system temperature $(T+)$, which will reduce heat losses

- A non-oversized boiler output (P+)

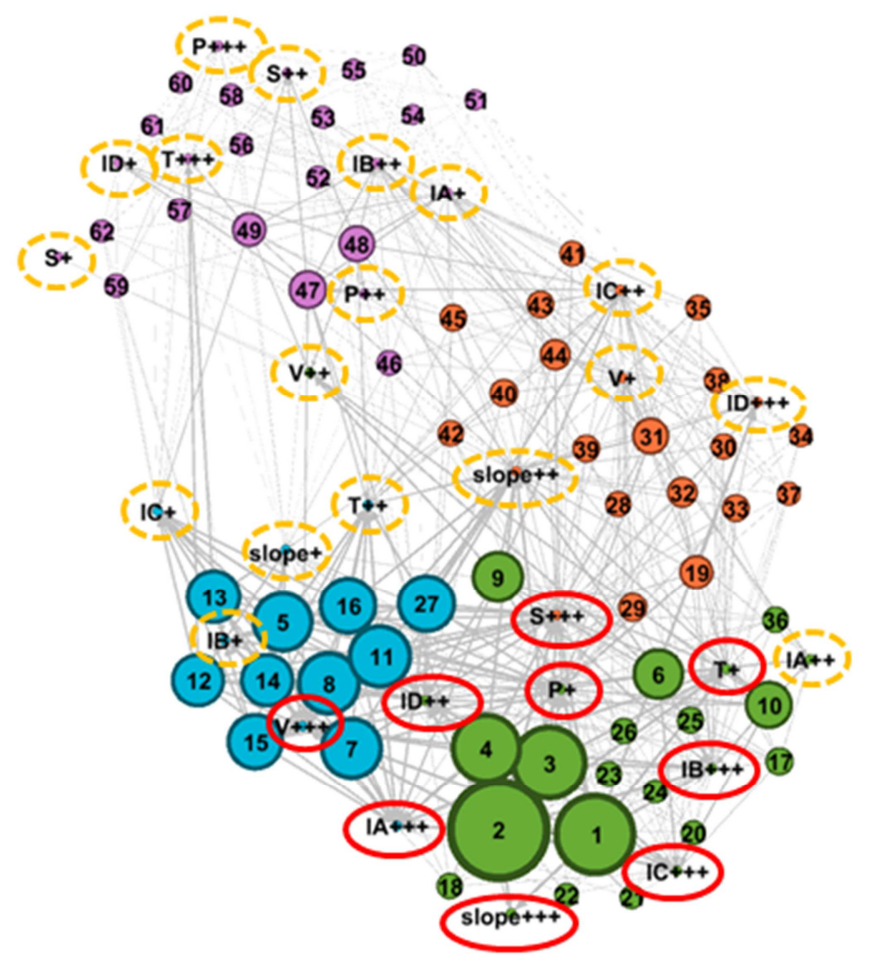

Figure 10: - The nodes of the 62 optimal solutions, linked to the corresponding values of the decision parameters (variation range divided into 3 partitions: $+/++/+++)$

If we compare solutions 1 and 2 (Figure 11), the difference in decision parameters is only related to the insulation thickness at the ground floor (ID ++ for solution $n^{\circ} 2$ and ID +++ for solution $n^{\circ} 1$ ). A lower thickness for the ground floor results in a lower investment cost and therefore a better LCC for the solution $n^{\circ} 2$. Figure 11 thus shows that the distance between the criterion LCC and the node of the solution $n^{\circ} 2$ is lower than that of the LCC and the node $n^{\circ} 1$. Therefore the overall satisfaction of solution 2 is better. 


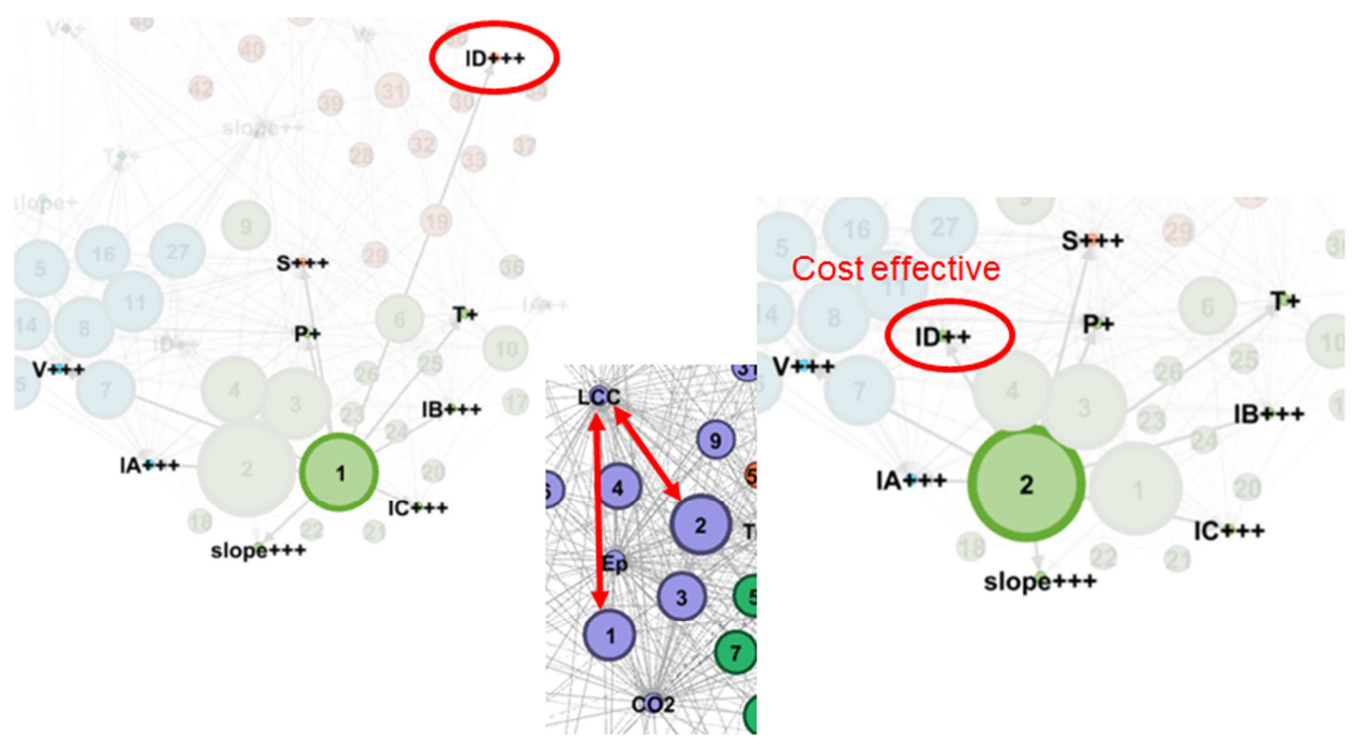

Figure 11: comparison of the solutions 1 and 2

Through this example, we can see that network modeling offers a new MCDA method. It is particularly powerful when the number of decision parameters and optimal solutions is high.

\section{Conclusion}

The study was carried out on two buildings for a total of 34 apartments. The TRNSYS / Energy + and Pleiades-Comfie tools were used for the validation of numerical models. We have developed optimization strategy $n^{\circ} 1$ based on the identification of kriging models with the maximum error observed on the SM. We plan to compare the four strategies using the TRNSYS software in a multi-zone configuration, also integrating a visual comfort criterion. In addition, we will optimize the other envelope configurations and systems presented. This work will be developed in the CADES generic tool (G2ELAB, VESTA SYSTEM), which is based on the use of software components for the design and optimization of multi-physical systems. It will integrate the four strategies of the general methodology and will allow using different dynamic simulation tools (TRNSYS, Energy $+\ldots$...). The considered SM will be of the kriging type. The results of this work will be available by the summer of 2018 within the framework of the INTENSE project. They will make it possible to compare the reduction of the calculation times obtained by the four strategies.

The notion of satisfaction function is a decision support tool that can be used to reduce computation time by reducing the optimal solutions area (solutions deemed unnecessary by the decision maker are discarded), and to choose the optimal solution (MCDA). We have shown with the case study that the graphical visualization of networks is a very relevant tool for decision-making. Even if the representation in a 2D plane of the network simplifies the problem very much, we have seen that the graphical exploitation is quite coherent.

Kriging models have the advantage of offering an estimate of the prediction error outside the individuals used for identification. This information is very useful when it comes to improving the meta-model (strategy $n^{\circ} 1$ ). On the other hand, they remain applicable for a 
limited number of inputs (about ten decision parameters). Under these conditions, other types of meta-models (MARS, neural networks, etc.) should be considered.

The reduction of computational times with meta-models can also be improved by performing parallel calculations. It is sufficient to define several new individuals in each loop rather than just one (Figure 1). Interoperability between software is an important issue that we have observed in the case of LCA, which requires a complex coupling with the dynamic simulation tool: parameters related to the composition of the building and exploitation of simulation results. Life cycle methodologies develop naturally because the reduction in annual consumption has highlighted the need to consider the embodied energy associated with construction. At the same time, taking climate change into account seems to be essential at the level of the life of new buildings. Under these conditions, the life-cycle should be taken into account when optimizing the design of NZEBs. A new challenge is clear in this context: taking into account uncertainties. It is obvious that optimization must become "robust" to overcome the uncertainties associated with the energy price evolution, climate change... Robust optimization requires additional simulations that accentuate the computation times and thus the interest of meta-models. It is therefore likely that the building sector is moving towards complex robust optimization methodologies that are multi-criteria, multidisciplinary, and using meta-models identified with suitable adaptive design of experiments.

Acknowledgments: This study has been supported and funded by the French National Research Agency (ANR), under grant agreement $N^{\circ}$ ANR-13-VBDU-0003-01, Acronym INTENSE. Partners: LOCIE, LGCB, ARMINES, G2ELAB, CEA-INES, ALBEDO, FAURE, VESTA SYSTEM

\section{References}

E. Antipova, D. Boer, G. Guillén-Gosálbez, L.F. Cabeza, L. Jiménez, Multi-objective optimization coupled with life cycle assessment for retrofitting buildings, Energy Build., 82, 2014, p. 92-99

Ascione, F., Bianco, N., De Stasio, C., Mauro, G. M., \& Vanoli, G. P. Artificial neural networks to predict energy performance and retrofit scenarios for any member of a building category: A novel approach. Energy, 118, 2017, p. 999-1017

Attia, S., Hamdy, M., O'Brien, W. and Carlucci, S. Assessing gaps and needs for integrating building performance optimization tools in net zero energy buildings design. Energy and Buildings, 60, 2013, p.110-124

Ayaz, E., \& Yang, F. (2009). Zero carbon isn't really zero: why embodied carbon in materials can't be ignored. Design Intelligence, Retrieved from http://www.di.net/articles/archive/zero carbon

Beccali M, Cellura M, Lo Brano V, Marvuglia A. Forecasting daily urban electric load profiles using artificial neural networks. Energy Convers Manag, 2004, 45:2879-900 
Belcher SE, Hacker JN, Powell DS. Constructing design weather data for future climates. Building Services Engineering Research and Technology, 2005, 26 (1): 49-61

G.A. Blengini, T. Di Carlo. The changing role of life cycle phases, subsystems and materials in the LCA of low energy buildings. Energy Build., 42 (6), 2010, p. 869-880

Bornatico, R., Hüssy, J., Witzig, A. and Guzzella, L. Surrogate modeling for the fast optimization of energy systems. Energy, 57, 2013, p.653-662

Boyd SP, Vandenberghe L. Convex optimization. Cambridge, UK: Cambridge University Press; 2004

Cao S, Hasan A, Sirén K. Analysis and solution for renewable energy load matching for a single-family house. Energy Build, 65, 2013, p. 398-411

Carreras, J., Pozo, C., Boer, D., Guillén-Gosálbez, G., Caballero, J.A., Ruiz-Femenia, R. and Jiménez, L. Systematic approach for the life cycle multi-objective optimization of buildings combining objective reduction and surrogate modeling. Energy and Buildings, 130, 2016, p.506-518

J. Carreras, D. Boer, G. Guillén-Gosálbez, L.F. Cabeza, M. Medrano, L. Jiménez, Multiobjective optimization of thermal modelled cubicles considering the total cost and life cycle environmental impact, Energy Build., 88, 2014, p. 335-346

T. Catalina, J. Virgone, E. Blanco, Multi-source energy systems analysis using A multi-criteria decision aid methodology, Renew. Energ. 36 (8), 2011, p. 2245-2252

Panagiotis Chastas, Theodoros Theodosiou, Dimitrios Bikas. Embodied energy in residential buildings-towards the nearly zero energy building: A literature review Review Article Building and Environment, Volume 105, 15 August 2016, Pages 267-282

Y. Chen and S. T. Ng, "Factoring in embodied GHG emissions when assessing the environmental performance of building," Sustainable Cities and Society, vol. 27, 2016, pp. 244-252

Cheng, M. Y., \& Cao, M. T. Accurately predicting building energy performance using evolutionary multivariate adaptive regression splines. Applied Soft Computing, 22, 2014, 178-188

Cherif, M.S., Chabchoub, H. and Aouni, B. Quality control system design through the goal programming model and the satisfaction functions. European Journal of Operational Research, 186(3), 2008, p.1084-1098

G. Comodi, A. Giantomassi, M. Severini, S. Squartini, F. Ferracuti, A. Fonti, D. Nardi, M. Morodo, F. Polonara. Multi-apartment residential microgrid with electrical and thermal storage devices: experimental analysis and simulation of energy management strategies. Appl. Energy, 137, 2014, p. 854-866 
Eguía, P., Granada, E., Alonso, J. M., Arce, E., \& Saavedra, A. Weather datasets generated using kriging techniques to calibrate building thermal simulations with TRNSYS. Journal of Building Engineering, 7, 2016, 78-91

Evins, R. A review of computational optimisation methods applied to sustainable building design. Renewable and Sustainable Energy Reviews, 22, 2013, p. 230-245

Eisenhower, B., O’Neill, Z., Narayanan, S., Fonoberov, V. A., \& Mezić, I. A methodology for meta-model based optimization in building energy models. Energy and Buildings, 47, 2012, 292-301

Fieldson, R., Rai, D., \& Sodagar, B. Towards a framework for early estimation of lifecycle carbon footprint of buildings in the UK. Construction Information Quarterly, 11(2), 2009, p. 66-75. ISSN 1469-4891

Friedman, J. H. (1991). Multivariate adaptive regression splines. The annals of statistics, 167.

R. Giordano, V. Serra, E. Demaria, A. Duzel. Embodied energy versus operational energy in a nearly zero energy building case study. Energy Procedia 111, 2017, p. $367-376$

Giordano R, Serra V, Tortalla E, Valentini V, Aghemo C. Embodied Energy and Operational Energy assessment in the framework of Nearly Zero Energy Building and Building Energy Rating. Energy Procedia 78, 2015, p. 3204-3209

C.J. Hopfe, M.T. Emmerich, R. Marijt, J.L.M. Hensen, Robust multi-criteria design optimisation in building design, In Proceedings of the building simulation and optimization conference. Loughborough, UK, 2012

T. Ibn-Mohammed, R. Greenough, S. Taylor, L. Ozawa-Meida, A. Acquaye Operational vs. embodied emissions in buildings-A review of current trends. Energy and Buildings 66, 2013, p. 232-245.

IEA. Promoting Energy efficiency investments. Case studies in the residential sector. https://www.iea.org/publications/freepublications/publication/PromotingEE2008.pdf. 2008.

Joseph Iwaro, Abrahams Mwasha, Rupert G. Williams, Ricardo Zico, An Integrated Criteria Weighting Framework for the sustainable performance assessment and design of building envelope, Renewable and Sustainable Energy Reviews 29, 2014, 417-434

Qian Jin, Fabio Favoino, Mauro Overend, Design and control optimisation of adaptive insulation systems for office buildings. Part 2: A parametric study for a temperate climate, Energy, Volume 127, 15 May 2017, p. 634-649

N. Kalkan, E.A. Young, A. Celiktas, Solar thermal air conditioning technology reducing the footprint of solar thermal air conditioning, Renew. Sustain. Energy Rev., 16, 2012, p. 63526383 
Kanarachos A, Geramanis K. Multivariable control of single zone hydronic heating systems with neural networks. Energy Convers Manag, 1998, 39, p. 1317-36

M. Karimpour, et al. Minimising the life cycle energy of buildings: review and analysis. Build. Environ., 73, 2014, p. 106-114

Kleijnen, J. P. Regression and Kriging metamodels with their experimental designs in simulation: a review. European Journal of Operational Research, 256(1), 2017, p. 1-16

K. Kontu, S. Rinne, V. Olkkonen, R. Lahdelma, P. Salminen, Multicriteria evaluation of heating choices for a new sustainable residential area, EnergyBuild. 93, 2015, p. 169-179

Kusiak, A., Li, M., \& Tang, F. Modeling and optimization of HVAC energy consumption. Applied Energy, 87(10), 2010, p. 3092-3102

Machairas, V., Tsangrassoulis, A. and Axarli, K. Algorithms for optimization of building design: A review. Renewable and Sustainable Energy Reviews, 31, 2014, p.101-112

Magnier, L., \& Haghighat, F. Multiobjective optimization of building design using TRNSYS simulations, genetic algorithm, and Artificial Neural Network. Building and Environment, 45(3), 2010, p. 739-746

A.J. Marszal, P. Heiselberg. Life cycle cost analysis of a multi-storey residential net zero energy building in Denmark. Energy, 36, 2011, p. 5600-5609

Emma Mulliner, Naglis Malys, Vida Maliene, Comparative analysis of MCDM methods for the assessment of sustainable housing affordability Original Research Article Omega, Volume 59, Part B, March 2016, p. 146-156

Nguyen, A. T., Reiter, S., \& Rigo, P. A review on simulation-based optimization methods applied to building performance analysis. Applied Energy, 113, 2014, p. 1043-1058

Penna, P., Prada, A., Cappelletti, F. and Gasparella, A. Multi-objectives optimization of Energy Efficiency Measures in existing buildings. Energy and Buildings, 95, 2015, p.57-69

Ramallo-González, A.P. and Coley, D.A. Using self-adaptive optimisation methods to perform sequential optimisation for low-energy building design. Energy and Buildings, 81, 2014, p.1829

T. Ramesh, R. Prakash, K.K. Shukla. Life cycle energy analysis of buildings: an overview. Energy Build., 42 (10), 2010, p. 1592-1600

Francesca Roberti, Ulrich Filippi Oberegger, Elena Lucchi, Alexandra Troi, Energy retrofit and conservation of a historic building using multi-objective optimization and an analytic hierarchy process Original Research Article, Energy and Buildings, Volume 138, 1 March 2017, p. 1-10

Charlotte Roux, Patrick Schalbart, Edi Assoumou, Bruno Peuportier, Integrating climate change and energy mix scenarios in LCA of buildings and districts, Applied Energy 184, 2016, p. 619-629 
Jin Si, Ljiljana Marjanovic-Halburd, Fuzhan Nasiri, Sarah Bel, Assessment of buildingintegrated green technologies: A review and case study on applications of Multi-Criteria Decision Making (MCDM) method, Sustainable Cities and Society 27, 2016, p. 106-115

Xinyan Song, Cantao Ye, Climate change adaptation pathways for residential buildings in southern China, Energy Procedia 105, 2017, p. 3062 - 3067

Terzidis, K. Algorithmic architecture. New York : Routledge. 2006.

E. Tresidder, Y. Zhang, A.I. Forrester, Acceleration of building design optimisation through the use of kriging surrogate models. Proceedings of the building simulation and optimization conference, September 2016, p. 2012

Van Gelder, L., Das, P., Janssen, H., \& Roels, S. Comparative study of metamodelling techniques in building energy simulation: Guidelines for practitioners. Simulation Modelling Practice and Theory, 49, 2014, p. 245-257

Robertas Volvačiovas, Zenonas Turskis, Donatas Aviža, Rūta Mikštienè, Multi-attribute Selection of Public Buildings Retrofits Strategy, Procedia Engineering, Volume 57, 2013, p. 1236-1241

Endong Wang, Neslihan Alp, Jonathan Shi, Chao Wang, Xiaodong Zhang, Hong Chen, Multicriteria building energy performance benchmarking through variable clustering based compromise TOPSIS with objective entropy weighting, Energy, Volume 125, 15 April 2017, p. 197-210

Wetter, M., \& Polak, E. A convergent optimization method using pattern search algorithms with adaptive precision simulation. Building services engineering research and technology, 25(4), 2004, p. 327-338

Wu, R., Mavromatidis, G., Orehounig, K. and Carmeliet, J. Multiobjective optimisation of energy systems and building envelope retrofit in a residential community. Applied Energy, 190, 2017, p.634-649

Zavala VM, Constantinescu EM, Krause T, Anitescu M. Weather forecast-based optimization of integrated energy systems. Technical report, Argonne National Laboratory; 2009. 
